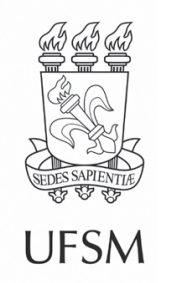

\title{
Artigos
}

\section{Avaliação do desempenho de painéis cimento-madeira fabricados com duas espécies florestais em combinação com casca de arroz}

\author{
Performance evaluation of wood-cement panels manufactured with two \\ forest species in combination with rice husk
}

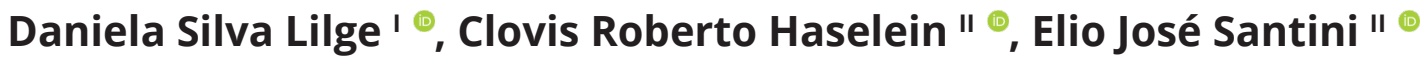 \\ ' Universidade Federal do Pampa, São Gabriel, RS, Brasil \\ " Universidade Federal de Santa Maria, Santa Maria, RS, Brasil
}

\section{RESUMO}

O presente trabalho objetivou avaliar o desempenho de painéis compostos de cimento e diferentes proporções de duas espécies de madeira combinadas com casca de arroz. Foram produzidos painéis experimentais cujas proporções de partículas de madeira utilizadas foram de 0-25-50-75 e 100\%, enquanto a proporção de cascas de arroz foi de 100-75-50-25 e 0\%, respectivamente. As espécies de madeiras utilizadas no estudo foram Eucalyptus grandis W. Hill ex Maiden e Pinus elliottii Engelm. Para determinar a qualidade dos painéis foram avaliadas as propriedades físicas (massa específica; absorção de água e inchamento em espessura após 2 e 24 horas de imersão) e as propriedades mecânicas (MOE e MOR em flexão estática e ligação interna), de acordo com a ASTM D-1037 (1999). Os resultados obtidos foram discutidos a partir da literatura, incluindo as recomendações do processo Bison (1978) para painéis cimento-madeira comerciais. Os painéis produzidos com partículas de pinus apresentaram desempenho nos testes de absorção e inchamento em espessura para imersão de 24 horas, inferior se comparado aos painéis fabricados com partículas de eucalipto. A adição de cascas de arroz, contudo, melhorou as propriedades físicas dos painéis fabricados tanto com partículas de pinus, quanto com partículas de eucalipto. Quanto maior a quantidade de cascas de arroz adicionada à chapa, menores foram as taxas de absorção de água e inchamento em espessura. As propriedades mecânicas dos painéis foram afetadas positivamente com a proporção de partículas de madeira. Sendo que o pinus apresentou melhores resultados para o módulo de elasticidade e a ligação interna; o eucalipto apresentou melhor performance para o módulo de ruptura. A adição de cascas de arroz representou perda de resistência mecânica para todos os tratamentos em todas as propriedades avaliadas.

Palavras-chave: Chapas cimento-madeira; Partículas de madeira; Compósitos 


\section{ABSTRACT}

The present paper aimed to evaluate the performance of panels composed by cement and different proportions of two combined wooden species with rice husk. Experimental panels were produced where the proportions of wood particles used were 0-25-50-75 and 100\%, while the proportion of rice husk was 100-75-50-25 and 0\%, respectively. The wood species in the study were Eucalyptus grandis W. Hill ex Maiden and Pinus elliottii Engelm. To determine the quality of the panels, the physical properties (density, water absorption and thickness swelling at 2 and 24 hours) and the mechanical resistance (static bending and internal bond) were evaluated according to ASTM D-1037 (1999). The results obtained were discussed using the literature, including the recommendations of the Bison (1978) process for woodcement commercial panels. The panels produced with pine particles presented larger water absorption and thickness swelling comparing to the panels manufactured with eucalypt particles. The addition of rice husk, however, improved the physical properties of the manufactured panels with particles of both species. Increasing the amount of rice husks, the panels showed less absorption of water and thickness swelling. The mechanical properties of the panels were affected positively with the addition of wood particles. The pine inclusion presented better results for the modulus of elasticity and the internal bond, while eucalypt inclusion presented better results in the modulus of rupture. The addition of rice husks represented loss of mechanical resistance for all the treatments in all the evaluated properties.

Keywords: Wood cement board; Wood particles; Composite

\section{INTRODUÇÃO}

A madeira, por ser um recurso natural renovável, de versátil utilização e baixo consumo energético em seu processamento industrial, torna-se um material cada vez mais requisitado em uma época em que a preocupação com o ambiente é cada vez maior.

A maior utilização da madeira como elemento construtivo colabora com a redução das emissões de carbono, visto que o lenho imobiliza carbono em sua massa até que sofra queima ou biodeterioração. Além disso, florestas plantadas capturam e imobilizam o carbono, realizando um balanceamento com as emissões de $\mathrm{CO}_{2}$. Uma vez que a concentração dessa molécula tem aumentado e vem contribuindo para o aquecimento global, essa característica da madeira é de grande importância para a natureza.

De acordo com Zucco (1999), a utilização de resíduos vegetais na obtenção de produtos para a construção é uma das ferramentas mais úteis para o controle e 
minimização dos problemas ambientais. A utilização de resíduos agroindustriais (como a casca de arroz e resíduos de serrarias) traz somente benefícios, pois evita a queima indiscriminada do material ou sua deposição em locais e em condições inadequadas. Beraldo (1994) indica ainda que a utilização de resíduos de origem vegetal na fabricação de compósitos de cimento poderia resultar em benefício ambiental pela redução do uso de recursos minerais, como a areia, cuja exploração agride intensamente o ambiente.

Os painéis de cimento-madeira são similares aos painéis aglomerados, tendo como diferenças o tipo de aglutinante (cimento) e o método de prensagem (à temperatura ambiente) (IWAKIRI et al., 2015). Esse produto tem uma larga aceitação na construção civil em países asiáticos e europeus. Entretanto, no Brasil, esse painel não está inserido comercialmente no mercado (POMARICO, 2013).

Segundo Lipinski (1994), ao unir cimento e madeira na confecção de painéis, o produto final terá menor densidade, maior resistência à tração e menor tendência ao surgimento de fissuras, características essas proporcionadas pela presença da madeira nas chapas. O cimento, por sua vez, proporciona ao painel uma maior resistência aos ataques biológicos, uma menor taxa de absorção de umidade ambiente e mais resistência ao fogo. De acordo com Pomarico (2013), os painéis cimento-madeira ainda apresentam boa trabalhabilidade e oferecem bom isolamento térmico e acústico. Essas são fortes razões para que esse compósito tenha uma boa aceitação no mercado brasileiro, no qual sua produção é ainda incipiente.

Esse material também pode ser encarado como fonte para substituição dos painéis de fibrocimento derivados do asbesto (amianto), que estão sendo banidos gradativamente em vários países do mundo (MACÊDO; SOUZA; POMPEU NETO, 2012). A toxicidade das chapas de cimento-amianto já foi provada e demonstrada e, mesmo no Brasil, sua utilização está sendo restringida e até proibida. A ausência do asbesto nas chapas de fibrocimento poderia ser sanada pelo uso de outro material fibroso. Pesquisas para adequar a madeira às exigências desse produto têm gerado resultados satisfatórios (PIMENTEL, 2000). 
Projetos de prédios públicos (escolas, postos de saúde, etc.), de casas populares e construções rurais podem ser implementados com o uso de painéis cimentomadeira. Esses compósitos auxiliam na industrialização da construção civil, visto que se prestam à construção de paredes, pisos e coberturas de forma modulada, em processos construtivos simples.

A inserção de resíduos de madeira na composição de painéis de cimento-casca de arroz agrega as características de resistência da madeira ao compósito. As partículas de madeira, de forma geral, possuem maior resistência mecânica se comparadas à casca de arroz, possuindo maior flexibilidade e resistência à ruptura.

Dessa maneira, o presente trabalho teve por objetivo avaliar o desempenho de painéis compostos de cimento e diferentes proporções de duas espécies de madeira (Eucalyptus grandis e Pinus elliottii) combinadas com casca de arroz.

\section{MATERIAIS E MÉTODOS}

\subsection{Preparo da matéria-prima}

Para realização deste trabalho, foram utilizadas partículas de madeira de Eucalyptus grandis W. Hill ex Maiden e Pinus elliottii Engelm, cascas de arroz, cimento Portland ARI-RS, aditivo e água.

As partículas de Eucalyptus grandis W. Hill ex Maiden (Figura 1) foram obtidas por desdobro de árvores de povoamentos florestais homogêneos de aproximadamente 15 anos, localizados no campus da Universidade Federal de Santa Maria (UFSM), na cidade de Santa Maria - RS. Primeiramente foram obtidas lascas com auxílio de moinho de facas, com corte ajustado para 0,55 mm de espessura. As dimensões das lascas foram de aproximadamente $50 \times 70 \times 0,55 \mathrm{~mm}$. As lascas foram reduzidas a partículas em moinho de martelos, equipado com peneira com malha de 8,0 mm de diâmetro. Por fim, o material foi submetido ao peneiramento em peneira com malha de 0,6 $\mathrm{mm}$ de diâmetro, para descarte dos finos. As partículas utilizadas foram submetidas à 
secagem ao ar livre até atingir o teor de umidade de equilíbrio.

As partículas de Pinus elliottii Engelm (Figura 1) foram fornecidas pela empresa Todesmade, situada no município de Cachoeira do Sul - RS. Sendo essas partículas oriundas do beneficiamento da madeira na marcenaria da empresa, tratava-se de maravalhas com dimensões entre 6 × 8 ×0,3 e $23 \times 15$ ×0,8 mm. Para homogeneização do material, utilizou-se o moinho de martelos, equipado com peneira com malha de $8 \mathrm{~mm}$ de diâmetro. Em seguida, realizou-se a seleção do material em peneira de 0,6 $\mathrm{mm}$ de diâmetro, para descarte dos finos. As partículas foram secas ao ar livre até atingirem o teor de umidade de equilíbrio e em seguida foram acondicionadas em sacos plásticos fechados e identificados.

As cascas de arroz (Figura 1) foram coletadas no Engenho Guidolin - Santa Maria e processadas em moinho de martelos, com peneira de $8 \mathrm{~mm}$. Em seguida, eliminaram-se os finos com auxílio de peneiras com $6 \mathrm{~mm}$ de malha. Como fase final da preparação do material casca de arroz, este foi lavado em solução de cal $\left[\mathrm{Ca}(\mathrm{OH})_{2}\right]$, como proposto por Serrano e Castro (1985) e Beraldo e Zucco (1998), com a finalidade de proporcionar melhoria da compatibilidade química entre a casca de arroz e o cimento. Assim, de acordo com o processo original, a quantidade de cal empregada foi de $5 \%$ da massa da casca, e a razão entre a solução de cal e a casca de arroz foi de 10:1. A fração utilizável de casca de arroz permaneceu em imersão total na solução de cal por um período de 24 horas, sofrendo agitação periódica para que a reação da cal com a casca de arroz ocorresse de forma correta. Em seguida, a solução foi descartada, as cascas foram lavadas para a remoção da cal e dos extrativos e colocadas ao ar livre para secagem, durante pelo menos 3 dias. Por fim, as cascas tiveram seu teor de umidade determinado. A armazenagem desse material se deu em sacos plásticos devidamente identificados e fechados.

O Cimento tipo Portland (CP-V-ARI RS), adquirido no comércio varejista, foi utilizado como material aglutinante. O cimento foi armazenado em sacos plásticos com capacidade de $5 \mathrm{~kg}$ cada. 
O aditivo utilizado na fabricação dos painéis foi o cloreto de cálcio di-hidratado $\left(\mathrm{CaCl}_{2} 2 \mathrm{H}_{2} \mathrm{O}\right)$ em pó, adquirido em sacos plásticos de 500 gramas. A utilização desse aditivo visou eliminar os efeitos inibitórios dos componentes químicos da madeira e acelerar o processo de cura do cimento.

Figura 1 - Partículas utilizadas na confecção dos painéis: $a=$ Eucalyptus grandis; $b=$ Pinus elliottii; c = casca de arroz

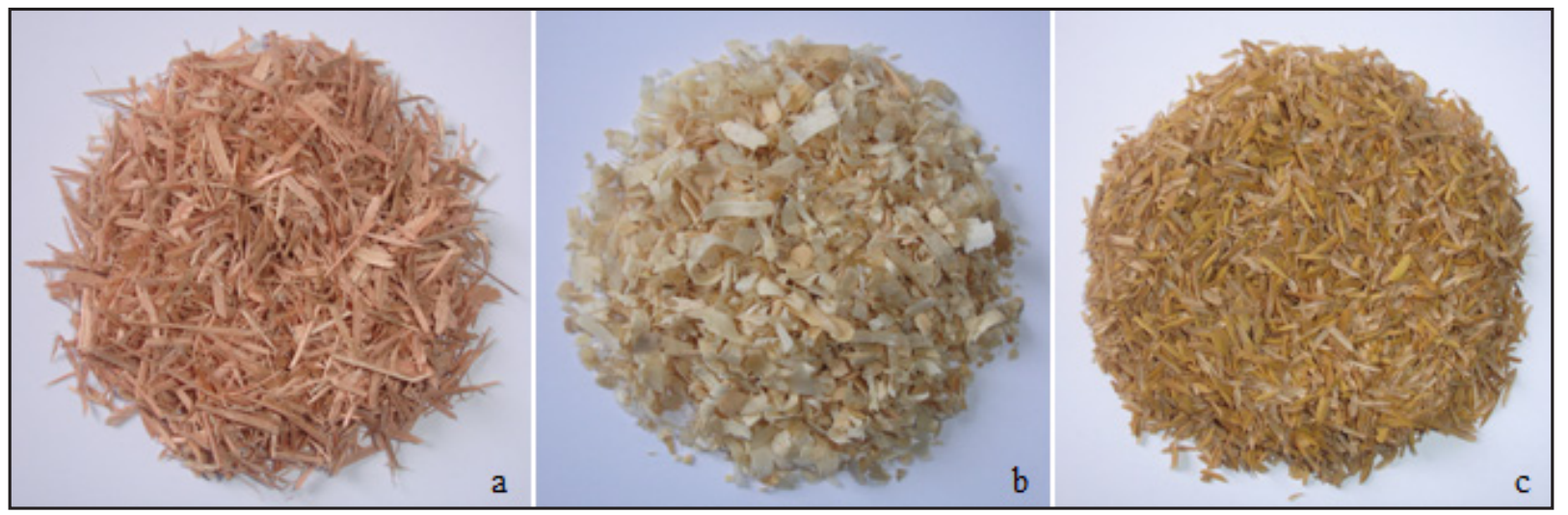

Fonte: Autores (2013)

A água utilizada foi fornecida diretamente pela rede pública de distribuição, por questão de praticidade e de economia, pois a água destilada ou tratada com fins específicos encarece a confecção desses painéis compósitos. O pH obtido no ponto de utilização foi de 7,0 .

\subsection{Produção dos painéis experimentais}

A metodologia de fabricação dos painéis baseou-se em Latorraca (2000) e Iwakiri et al. (2012). O cálculo das quantidades de cada um dos componentes para fabricação dos painéis baseou-se na metodologia de Latorraca (2000) e Souza (1994). Dessa forma, os painéis foram produzidos com: densidade de 1,25 g/ $\mathrm{cm}^{3}$; taxa de biomassa vegetal: cimento de 0,364; taxa de água: cimento de 0,45; taxa de água de hidratação: cimento de 0,25 e taxa de aditivo: cimento de 0,03. Vale ressaltar que a taxa de água: hidratação:cimento é fixa e se refere à água que está vinculada ao cimento após a hidratação. 
O delineamento experimental utilizado foi inteiramente casualizado e os painéis produzidos possuíam $50 \mathrm{~cm}$ de aresta e 9,5 mm de espessura. Foram confeccionados 3 painéis para cada tratamento proposto (9 tratamentos), conforme apresentado na Tabela 1, totalizando 27 painéis de cimento-madeira-casca de arroz.

Tabela 1 - Tratamentos desenvolvidos no experimento

\begin{tabular}{lccc}
\hline \multirow{2}{*}{ Tratamentos } & \multicolumn{3}{c}{ Fatores } \\
\cline { 2 - 4 } & Eucalipto (\%) & Pinus (\%) & Casca de arroz (\%) \\
\hline 1 & 100 & 0 & 0 \\
2 & 75 & 0 & 25 \\
3 & 50 & 0 & 50 \\
4 & 25 & 0 & 75 \\
5 & 0 & 100 & 0 \\
6 & 0 & 75 & 25 \\
7 & 0 & 50 & 50 \\
8 & 0 & 25 & 75 \\
9 & 0 & 0 & 100 \\
\hline
\end{tabular}

Fonte: Autores (2013)

Utilizando-se de sistema de ar comprimido (aspersor), o aditivo químico, diluído na água, foi aspergido sobre as partículas previamente colocadas em betoneira em movimento. A hidratação do material vegetal com essa solução durou dois minutos. Em seguida, a betoneira foi desligada. No passo seguinte, foi adicionado o cimento e mantevese a betoneira em funcionamento durante mais dois minutos.

Logo, a mistura foi retirada da betoneira, pesada em balança analítica e colocada na caixa formadora do colchão, que, por sua vez, estava disposta sobre uma chapa de aço coberta com plástico para que a mistura do painel não aderisse à chapa. A caixa formadora possui aresta interna de $50 \mathrm{~cm}$ e constitui-se de uma caixa de madeira sem fundo com uma tampa que nela é inserida após a colocação do material que formará o colchão. Após colocada a tampa, a mesma foi fixada e pressionada sobre o colchão durante um minuto.

Em seguida, retirou-se a caixa formadora e colocou-se um espaçador de aço de 9,5 $\mathrm{mm}$ de espessura de cada lado do colchão, com o objetivo de delimitar a espessura final 
do painel. Cobriu-se o conjunto com plástico e com outra chapa de aço e levou-se o mesmo à prensa. A prensagem foi efetuada com aplicação de $15 \mathrm{kgf} / \mathrm{cm}^{2}$, a frio, durante 24 horas, em prensa hidráulica da marca OMECO. Foram prensados 3 colchões simultaneamente, um sobre o outro.

Após a prensagem, os painéis foram levados à câmara climatizada, sendo, dessa forma, submetidos à temperatura constante de $20^{\circ} \mathrm{C}$ e umidade relativa de $65 \%$. A permanência destes na câmara foi de 28 dias, completando, assim, o processo de maturação dos painéis.

Após o período de maturação, os painéis foram cortados para confecção dos corpos de prova para os testes de flexão estática, ligação interna (tração), inchamento e absorção d'água. O corte foi feito em serra circular e as dimensões dos corpos de prova foram determinadas de acordo com a norma ASTM D-1037 (1999).

Foram descartados $50 \mathrm{~mm}$ de cada uma das laterais dos painéis, sendo que o modelo de corte utilizado para confecção dos corpos de prova pode ser observado na Figura 2.

Figura 2 - Modelo de corte dos painéis para confecção dos corpos de prova (medidas em mm)

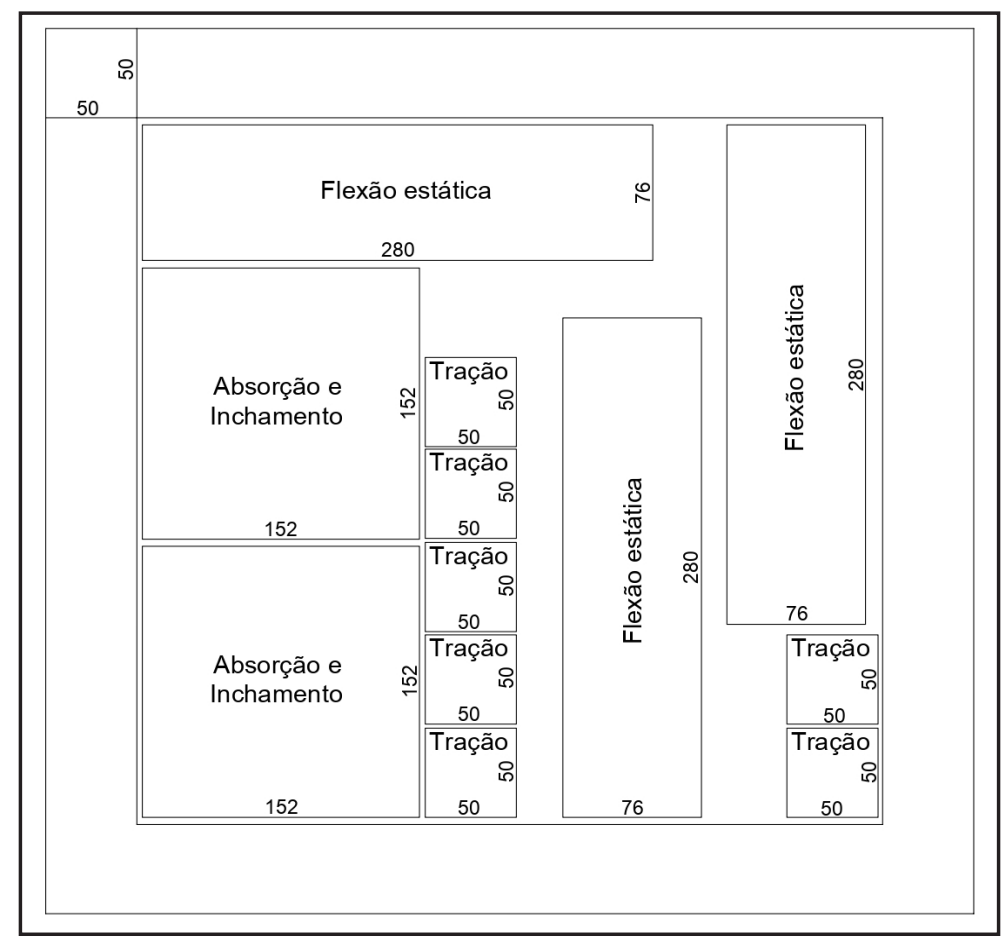

Fonte: Autores (2013) 


\subsection{Avaliação dos painéis - testes físico-mecânicos}

Todos os testes mecânicos foram realizados em máquina universal de ensaios, da marca Amsler, com capacidade de 20 toneladas, pertencente ao Laboratório de Produtos Florestais da UFSM. Os pares de dados de carga e deslocamento foram alimentados automaticamente por uma placa de aquisição de dados, inserida em um computador IBM PC.

Para determinação do módulo de elasticidade e do módulo de ruptura foi realizado teste de flexão estática, segundo a norma ASTM D-1037 (1999). Assim, foram necessários corpos de prova com comprimento igual a 24 vezes a sua espessura nominal, com adição de $50 \mathrm{~mm}$, o que, no presente trabalho, representa $278 \mathrm{~mm}$ de comprimento e $76 \mathrm{~mm}$ de largura nominal.

O corpo de prova biapoiado em suportes cuja distância entre eles foi de 24 vezes a espessura nominal, sofreu a aplicação de carga em sua porção central. A velocidade de aplicação de carga foi regulada de acordo com a equação sugerida pela norma, obtendo-se um valor de $0,47 \mathrm{~mm} / \mathrm{min}$. Os valores coletados foram enviados diretamente a um computador IBM PC.

O ensaio de tração perpendicular, que visa determinar a adesão interna do painel, foi realizado segundo a norma ASTM D-1037 (1999), que determina a utilização de corpos de prova quadrados com aresta de $50 \pm 1 \mathrm{~mm}$. As faces dos corpos de prova foram coladas em blocos de aço que serviram de suporte, os quais foram tracionados em direções opostas, de forma a proporcionar o rompimento do corpo de prova. A velocidade do teste foi ajustada de acordo com a norma, com base na espessura dos corpos de prova, em 0,76 mm/min. A adesão interna (Al) foi calculada por meio da relação entre carga máxima e área de esforço, expressos em kgf/cm².

A massa específica aparente foi determinada de acordo com a norma ASTM D-1037 (1999), em todos os corpos de prova, de todos os testes (físicos e mecânicos) antes dos mesmos serem realizados. As peças se encontravam com teor de umidade 
de equilíbrio em câmara climatizada (12\%). As pesagens foram realizadas em balança analítica e as medidas, para determinação do volume, foram aferidas com o uso de paquímetro.

Os testes de inchamento em espessura e absorção de água foram realizados de acordo com a norma ASTM D-1037 (1999), que determina a utilização de corpos de prova de $152 \pm 1 \mathrm{~mm}$ de aresta, que foram submetidos à imersão em água por períodos de 2 e de 24 horas. Os corpos de prova foram cobertos por $25 \mathrm{~mm}$ de água, com pH 7, a aproximadamente $20^{\circ} \mathrm{C}$.

No teste de inchamento em espessura, a espessura dos corpos de prova foi medida na intersecção de suas diagonais, antes e após a imersão em água, após 2 horas e após 24 horas de imersão. Para medição da espessura, foi utilizado relógio comparador e, para aferição de comprimento e largura, foi utilizado paquímetro digital.

\section{RESULTADOS E DISCUSSÃO}

\subsection{Propriedades físicas dos painéis de cimento-madeira-casca de arroz}

Os valores médios de massa específica, da absorção de água em 2 e 24 horas de imersão e do inchamento em espessura em 2 e 24 horas de imersão, para todos os tratamentos avaliados são apresentados na Tabela 2.

A massa específica dos painéis variou entre 1,13 g/ $\mathrm{cm}^{3}$ e 1,26 g/ $/ \mathrm{cm}^{3}$, sendo que o valor esperado na produção dos mesmos era de 1,25 g/cm³. A variação da massa específica de painéis cimento-madeira deve-se às condições de manufatura em laboratório, e é a falta de homogeneidade na distribuição manual da mistura, para formação do painel, a principal responsável por essa variação (HILLIG, 2000; DACOSTA, 2004). Contudo, os valores obtidos para densidade aproximam-se do requerido pelo processo Bison (1978) para painéis comerciais, que é de $1,1 \mathrm{~g} / \mathrm{cm}^{3}$.

Os valores médios de absorção d'água, alcançados nos períodos de 2 e 24 horas 
de imersão variaram de 11,08 a 16,71\% e de 14,08 a 20,45\%, respectivamente. Os painéis fabricados exclusivamente com casca de arroz tiveram menor taxa de absorção d'água, se comparados aos painéis que continham mais madeira em sua composição. A adição de partículas de madeira fez com que o grau de absorção aumentasse gradativamente em níveis diferentes para cada uma das espécies estudadas. Os painéis fabricados com pinus demonstraram ligeira desvantagem na absorção em período de 24 horas, pois suas médias de absorção foram maiores que as das chapas de eucalipto.

Tabela 2 - Valores médios de massa específica, absorção de umidade e inchamento em espessura após 2 e 24 horas de imersão dos painéis

\begin{tabular}{lccccc}
\hline Tratamento & $\begin{array}{c}\text { Massa } \\
\text { específica } \\
\text { (g/cm } \mathbf{3})\end{array}$ & $\begin{array}{c}\text { Absorção } \\
\mathbf{2 h} \mathbf{( \% )}\end{array}$ & $\begin{array}{c}\text { Absorção } \\
\mathbf{2 4 h} \mathbf{( \% )}\end{array}$ & $\begin{array}{c}\text { Inchamento } \\
\mathbf{2 h} \mathbf{( \% )}\end{array}$ & $\begin{array}{c}\text { Inchamento } \\
\mathbf{2 4 h}(\mathbf{\%})\end{array}$ \\
\hline 1 & 1,14 & 16,71 & 19,75 & 0,49 & 12,74 \\
2 & 1,18 & 14,72 & 18,13 & 0,41 & 11,24 \\
3 & 1,17 & 13,37 & 16,90 & 0,33 & 7,58 \\
4 & 1,21 & 12,08 & 15,52 & 0,25 & 3,75 \\
5 & 1,14 & 15,21 & 20,45 & 1,43 & 15,77 \\
6 & 1,13 & 13,92 & 19,03 & 1,06 & 12,77 \\
7 & 1,16 & 12,97 & 17,33 & 0,79 & 8,12 \\
8 & 1,16 & 12,28 & 15,84 & 0,46 & 4,80 \\
9 & 1,26 & 11,08 & 14,08 & 0,15 & 1,30 \\
\hline
\end{tabular}

Fonte: Autores (2013)

Em que: Tratamento 1 (Eucalipto 100\%_Pinus 0\%_Casca 0\%); T2 (E75_PO_CC25); T3 (E50_P0_ CC50); T4 (E25_P0_CC75); T5 (E0_P100_CCO); T6 (E0_P75_CC25); T7 (E0_P50_CC50); T8 (E0_ P25_CC75); T9 (E0_PO_CC100).

Pimentel (2000), avaliando compósitos à base de cimento e partículas de Pinus, obteve um valor médio de absorção de 20,26\%, valor muito próximo ao encontrado no presente estudo em painel manufaturado com partículas de Pinus e sem adição de casca de arroz.

Latorraca (2000), trabalhando com diversas espécies de eucalipto em chapas de cimento-madeira, obteve índices de absorção variando de 12,9 a 20,27\%. Os valores de absorção após 24 horas de imersão dos painéis manufaturados com partículas de 
eucalipto, neste estudo, encontram-se dentro da faixa de variação obtida pelo referido autor.

Analisando a absorção d'água em 24 horas de imersão em função da porcentagem de madeira e, consequentemente, da porcentagem de casca de arroz, as melhores equações ajustadas, tanto para os tratamentos com partículas de eucalipto quanto para aqueles com resíduos de pinus, apresentaram valor de $\mathrm{P}$ menor que 0,01, relacionando a significância estatística entre as variáveis para um nível de confiança maior que $99 \%$.

A Figura 3 demonstra os gráficos com os valores observados e os modelos de regressão para absorção d'água dos tratamentos após 24 horas de imersão.

Figura 3 - Valores de absorção d'água após 24 horas de imersão (Ab - 24h) observados e ajustados em função da porcentagem de partículas de Eucalyptus grandis e Pinus elliottii

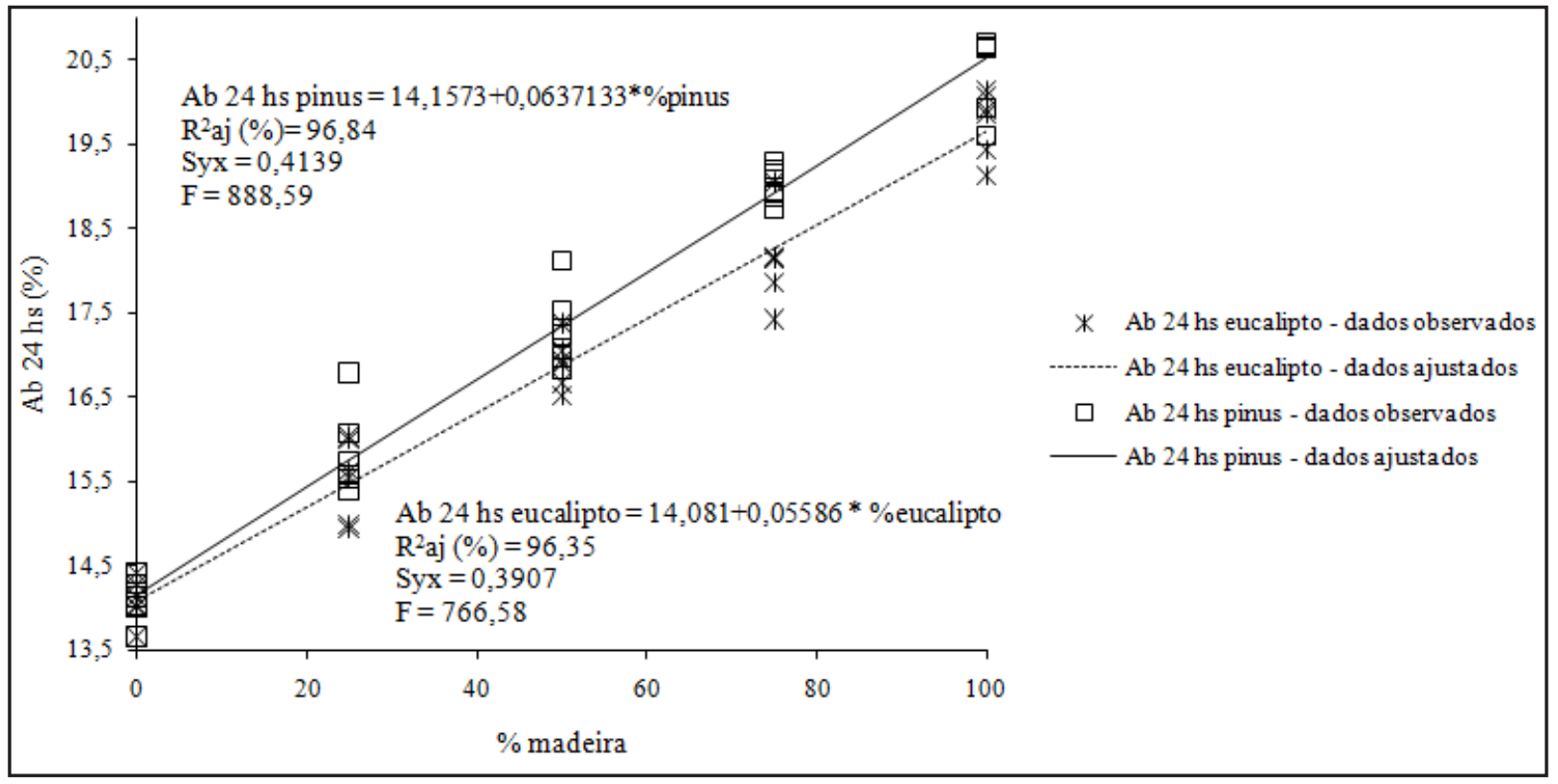

Fonte: Autores (2013)

Os valores médios de inchamento em espessura (IE) variaram de 0,15 a 1,43\% para 2 horas de imersão e de 1,30 a 15,77\% para 24 horas de imersão. Esses resultados demonstram que, conforme a quantidade de partículas de madeira diminui na 
composição dos painéis, menores são os valores de inchamento, para as duas espécies florestais em questão. Isso indica um acréscimo no comportamento de resistência à ação da água, à medida que é adicionada mais casca de arroz na manufatura das chapas.

Os painéis fabricados com partículas de pinus apresentaram médias superiores àqueles fabricados apenas com cascas de arroz ou então com eucalipto, demonstrando assim uma maior taxa de inchamento em espessura, se comparados aos painéis feitos à base das outras matérias-primas avaliadas.

Observa-se que, com o passar do tempo, os valores de IE tendem a apresentar menores diferenças se forem comparadas as duas espécies florestais em questão. Assim, inicialmente (IE - 2h), ocorreu um IE notadamente maior nos painéis com partículas de pinus em sua composição. Na avaliação de IE em imersão de 24 horas, os valores dessa variável para pinus continuaram maiores, porém suas diferenças em relação aos tratamentos contendo eucalipto são mais discretas do que no início.

Latorraca (1996), estudando o comportamento de Eucalyptus dunnii em painéis de cimento-madeira, identificou valores de inchamento em espessura próximos aos encontrados neste trabalho, com médias variando de 2,58 até 10,38\% para essa espécie.

Matoski (2005), avaliando o comportamento da granulometria de partículas de pinus em compósitos cimento-madeira, obteve resultados de IE, após 24 horas de imersão, variando de 0,46 a 2,22\%. Os valores observados no presente estudo encontram-se acima dos apresentados pelo mencionado autor. Isso se deve às diferenças das relações madeira:cimento adotadas nos trabalhos, uma vez que Matoski (2005) utilizou uma relação de 0,25, enquanto este estudo considerou uma relação de 0,364.

Os resultados obtidos para inchamento em espessura após 2 horas de teste foram excelentes se levada em consideração a exigência máxima do processo Bison (1978), que é de 1,2\%. Apenas o tratamento 5 apresentou valor um pouco acima do 
recomendado (1,43\%). Entretanto, no que se refere ao inchamento após 24 horas de imersão, apenas o tratamento 9 (100\% de casca de arroz) obteve resultado abaixo $(1,30 \%)$ do máximo exigido (1,8\%) pelo processo anteriormente citado. Isso é um indicativo da menor higroscopicidade da casca de arroz em relação à madeira. Esses resultados indicam também a necessidade de tratamento hidrófugo dos painéis, com a finalidade de aprimorar seu desempenho.

Os dados observados e as equações ajustadas para as duas espécies de partículas de madeira estudadas em relação ao inchamento em espessura em imersão de 24 horas encontram-se na Figura 4.

Figura 4 - Valores de inchamento em espessura após 24 horas de imersão (Ab - 24h) observados e ajustados em função da porcentagem de partículas de Eucalyptus grandis e Pinus elliottii

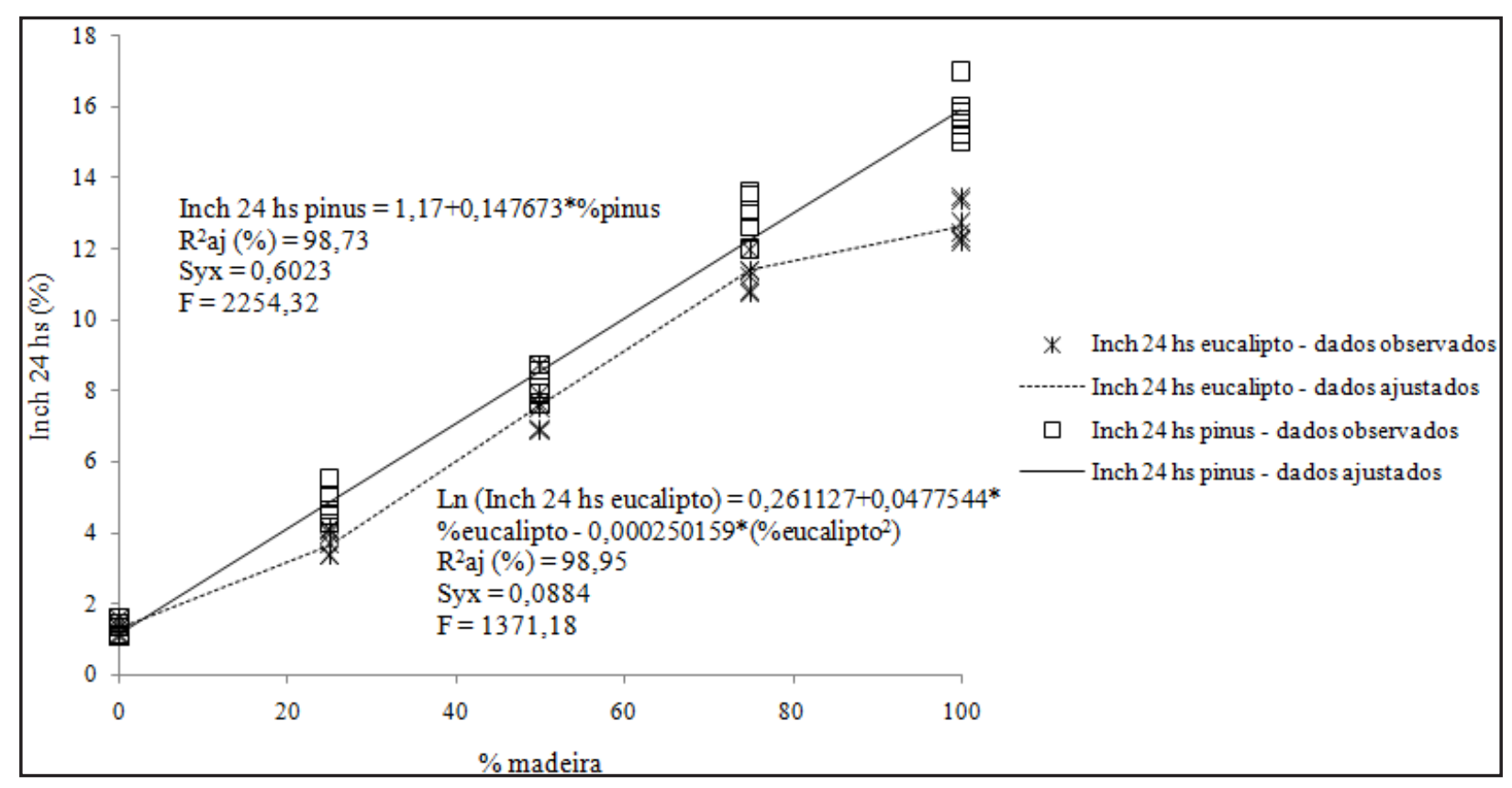

Fonte: Autores (2013)

\subsection{Propriedades mecânicas dos painéis de cimento-madeira-casca de arroz}

Os valores médios de módulo de elasticidade (MOE), módulo de ruptura (MOR) 
e resistência à tração perpendicular (LI), para todos os tratamentos avaliados são apresentados na Tabela 3.

Tabela3 - Valores médios relativos aos testes mecânicos das chapas

\begin{tabular}{lccc}
\hline Tratamento & MOE (kgf/cm $\mathbf{c}^{2}$ & $\begin{array}{c}\text { MOR } \\
\left(\mathbf{k g f} / \mathbf{c m}^{2}\right)\end{array}$ & LI (kgf/cm $\mathbf{~})$ \\
\hline 1 & 24692 & 121,53 & 9,38 \\
2 & 24258 & 96,99 & 6,79 \\
3 & 19999 & 78,61 & 5,31 \\
4 & 16980 & 71,03 & 3,70 \\
5 & 44160 & 99,85 & 12,15 \\
6 & 30618 & 86,56 & 8,70 \\
7 & 21984 & 71,92 & 6,88 \\
8 & 17823 & 61,72 & 4,93 \\
9 & 14139 & 65,57 & 4,04 \\
\hline
\end{tabular}

Fonte: Autores (2013)

Em que: $\mathrm{MOE}=$ Módulo de elasticidade; $\mathrm{MOR}=$ Módulo de ruptura; $\mathrm{LI}$ = resistência à tração perpendicular do painel ou ligação interna; T1 (E100_P0_CC0); T2 (E75_P0_CC25); T3 (E50_P0_ CC50); T4 (E25_P0_CC75); T5 (E0_P100_CC0); T6 (E0_P75_CC25); T7 (E0_P50_CC50); T8 (E0_P25_ CC75); T9 (EO_PO_CC100).

Os valores médios de módulo de elasticidade (MOE) variaram, em função da proporção de resíduos de madeira, de 14.139 a $44.160 \mathrm{kgf} / \mathrm{cm}^{2}$. Verifica-se que os maiores valores de MOE foram obtidos para tratamentos à base de pinus, sendo que a adição progressiva de cascas de arroz fez com que o módulo sofresse diminuição de seus valores. O MOE nos painéis à base de eucalipto também sofreu diminuição conforme foi adicionada casca de arroz à composição.

O módulo de ruptura (MOR), por sua vez, apresentou valores médios entre 61,72 e 121,53 kgf/cm². O MOR foi maior nos painéis compostos por partículas de eucalipto, sendo que a adição de cascas de arroz também gerou efeito negativo na resistência das chapas. Comportamento similar pôde ser observado nos compósitos manufaturadas com resíduos de pinus.

O pior desempenho, tanto para MOE, quanto para MOR foi observado nos 
painéis compostos apenas de cimento e casca de arroz, indicando que a adição desse material em painéis tende a diminuir resistência das chapas produzidas.

Latorraca (1996), trabalhando com compósitos de cimento-madeira de Eucalyptus dunnii e utilizando $\mathrm{CaCl}_{2}$ como aditivo, verificou valores de MOE entre 24.083 e 29.178 $\mathrm{kgf} / \mathrm{cm}^{2}$. Pode-se observar que os valores obtidos neste trabalho, utilizando o mesmo tratamento químico (aditivo) e partículas do mesmo gênero florestal, aproximam-se daqueles obtidos pelo autor supracitado.

Matoski (2005), trabalhando com resíduos de pinus de diferentes granulometrias, observou, em painéis fabricados com cloreto de cálcio como aditivo, valores de MOE entre $24.684,3$ e $32.708,5 \mathrm{kgf} / \mathrm{cm}^{2}$. Nessa situação, os valores encontrados pelo referido autor se aproximam dos resultados observados neste estudo.

No entanto, apenas os tratamentos 5 e 6, (com maiores quantidades de partículas de pinus na sua composição), atendem ao mínimo exigido por Bison (1978) para painéis comerciais, que é de $30.000 \mathrm{kgf} / \mathrm{cm}^{2}$.

Carvalho (2000), avaliando o desempenho de Eucaliptus grandis na fabricação de painéis cimento-madeira, encontrou valores de MOR variando entre 27,5 e 66,5 $\mathrm{kgf} / \mathrm{cm}^{2}$. Os valores de MOR observados neste estudo foram maiores se comparados aos obtidos por Carvalho (2000), isso provavelmente se deve ao fato do referido autor não ter utilizado nenhum aditivo para controle da incompatibilidade entre cimento e madeira, gerando, assim, resultados inferiores aos desta pesquisa. Estudos como o de Latorraca (1996) indicam que a utilização de aditivos, como o $\mathrm{CaCl}_{2}$ e $\circ \mathrm{MgCl}_{2}$, proporciona desempenho melhor do MOR, em comparação a tratamentos de lavagem das partículas de madeira em painéis que utilizam resíduos de eucalipto.

Para o mesmo aditivo utilizado neste trabalho, Matoski (2005) encontrou valores de MOR, para painéis manufaturados com resíduos de pinus, variando entre 51,67 e $60,35 \mathrm{kgf} / \mathrm{cm}^{2}$. Os valores aqui encontrados situam-se acima daqueles observados pelo autor. Isso pode ser justificado pela menor proporção de madeira utilizada por Matoski (2005) em seu estudo, pois, como se pode observar, quanto maior a porcentagem de 
madeira aplicada na composição dos painéis, maior o MOR dos mesmos.

Por outro lado, apenas os tratamentos 1, 2 e 5 (com maiores quantidades de madeira em sua composição) atenderam à exigência mínima (90 kgf/cm²) do processo Bison (1978) para painéis comerciais.

Analisando o MOE em função da porcentagem de madeira, as melhores equações ajustadas para os tratamentos encontram-se na Figura 5.

Figura 5 - Valores de módulo de elasticidade (MOE) observados e ajustados em função da porcentagem de partículas de Eucalyptus grandis e Pinus elliottii

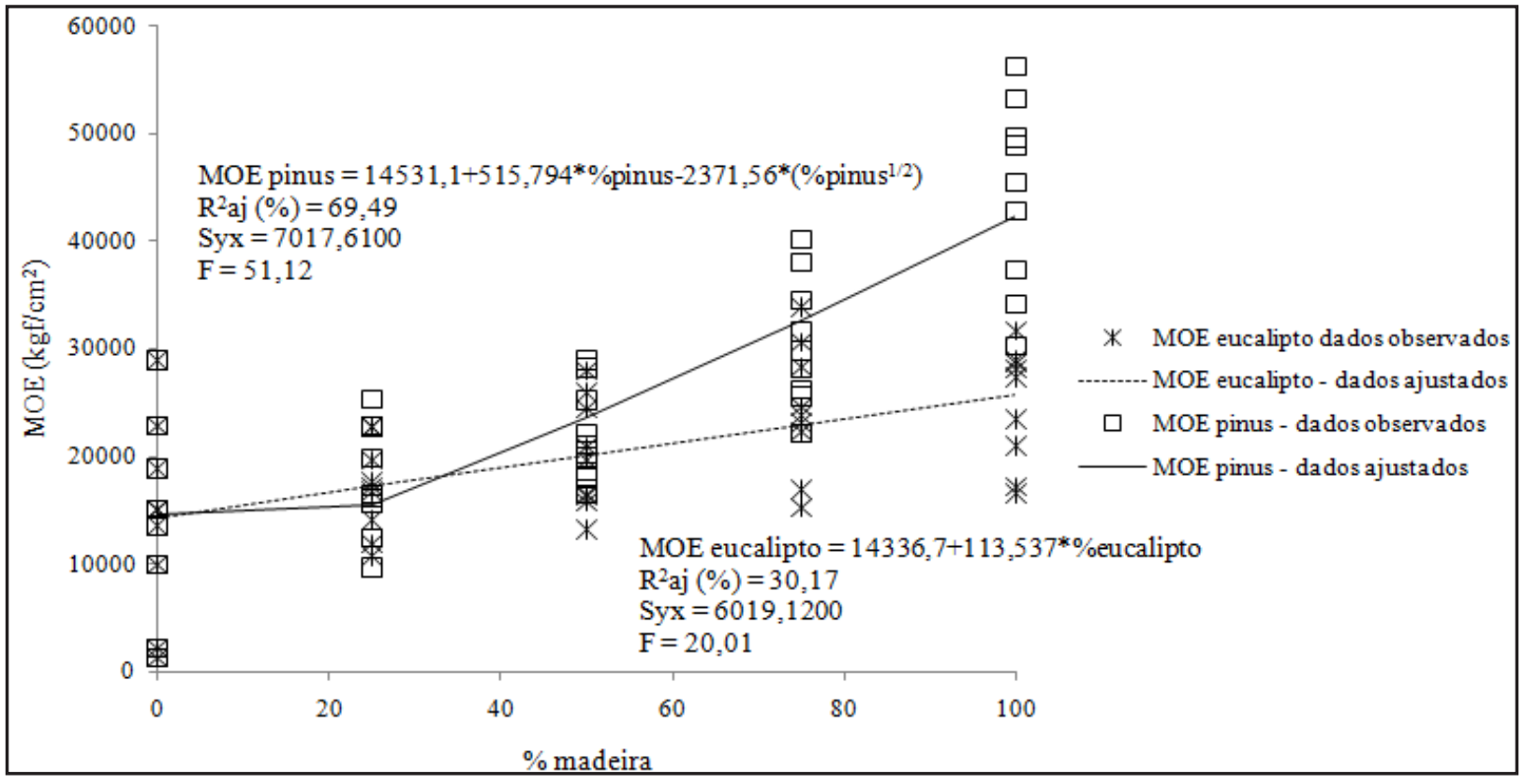

Fonte: Autores (2013)

Na Figura 6, encontram-se os modelos ajustados e os dados observados para o módulo de ruptura durante os testes de flexão estática.

Os valores observados para resistência à tração perpendicular estão entre 3,70 e 12,15 kgf/ $\mathrm{cm}^{2}$. É notável o melhor desempenho das chapas manufaturadas com partículas de pinus se comparado ao daquelas fabricadas com partículas de eucalipto. Pode-se afirmar que a adição de cascas de arroz prejudicou o desempenho dos painéis no aspecto resistência à tração perpendicular, de forma que quanto mais desse componente foi agregado aos compósitos, menores foram os valores de LI. 
Latorraca (1996), analisando o desempenho de chapas de cimento-madeira de partículas de Eucalyptus dunnii, encontrou valores de LI em torno de 0,37 a 1,22 kgf/ $\mathrm{cm}^{2}$. Esses valores encontram-se bem abaixo dos observados no presente estudo. A utilização de cimento comum, ao invés de cimento Portland V ARI RS, que suporta melhor as incompatibilidades das matérias-primas vegetais com o cimento, é a provável causa da diferença entre os valores aqui observados e aqueles gerados no trabalho do referido autor.

Figura 6 - Valores de módulo de ruptura (MOR) observados e ajustados em função da porcentagem de partículas de Eucalyptus grandis e Pinus elliottii

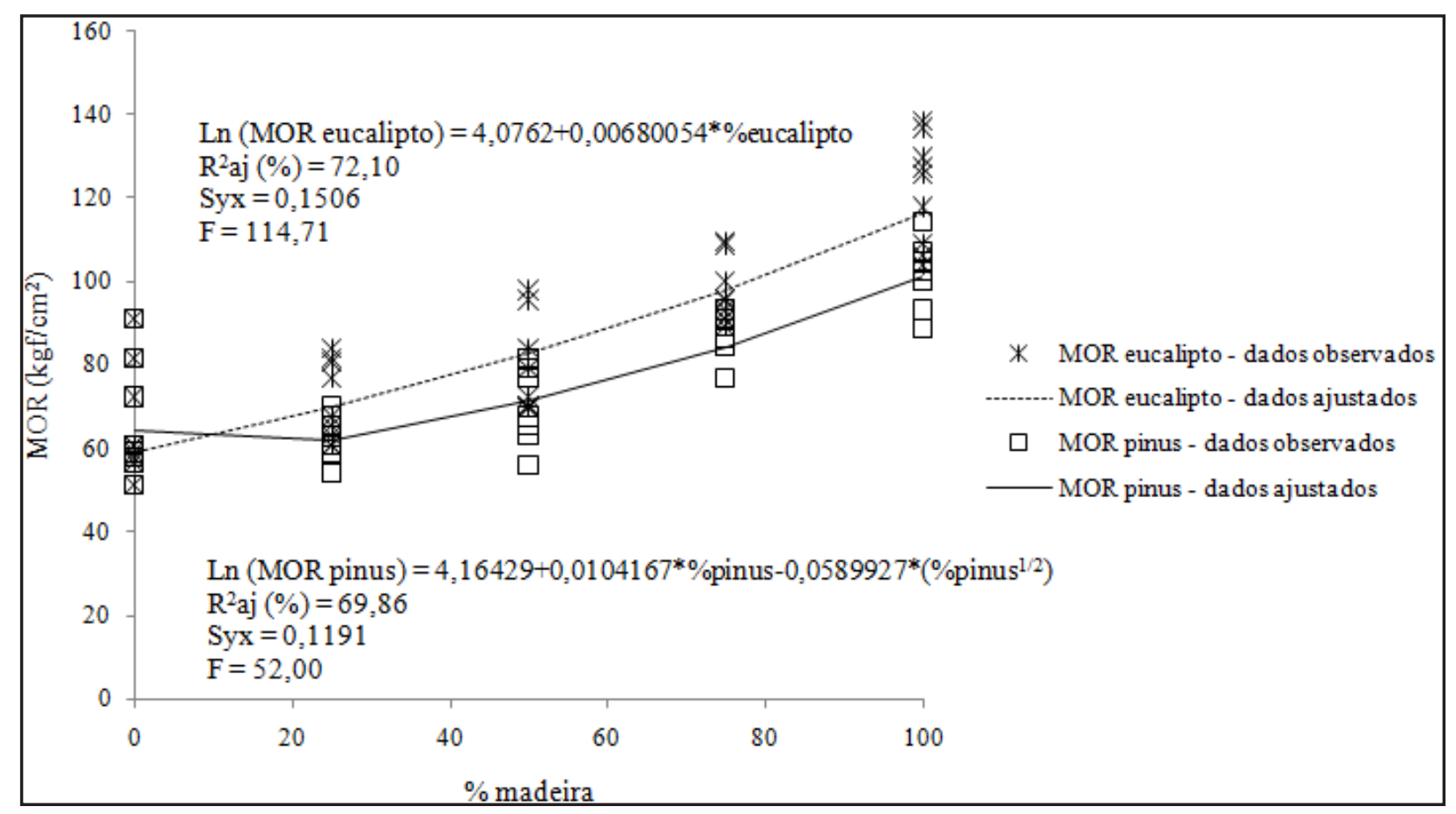

Fonte: Autores (2013)

Trabalhando com resíduos de pinus, Matoski (2005) observou valores de LI entre 1,10 e 7,66 kgf/cm². Considerando que esse autor utilizou uma relação de madeira:cimento $(0,25)$ menor do que a usada neste estudo $(0,364)$ e tendo em vista que quanto maior a quantidade de madeira nos painéis maior sua resistência à tração perpendicular, justificam-se os valores maiores de LI aqui encontrados. 
Todos os tratamentos, com exceção do tratamento 4 (25\% de eucalipto e $75 \%$ de cascas de arroz), atenderam a exigência mínima (4 kgf/cm²) do processo Bison (1978) para painéis comerciais.

A significância estatística entre os valores de LI e as porcentagens de madeira nos modelos ajustados a partir dos dados observados geraram um nível de confiança maior de $99 \%(P<0,01)$, tanto para os tratamentos que envolveram partículas de pinus quanto para aqueles que continham em sua composição partículas de eucalipto.

Na Figura 7 é possível observar os modelos e os dados obtidos nos ensaios de LI para as duas espécies florestais.

Figura 7 - Valores de resistência à tração perpendicular (LI) observados e ajustados em função da porcentagem de partículas de Eucalyptus grandis e Pinus elliottii

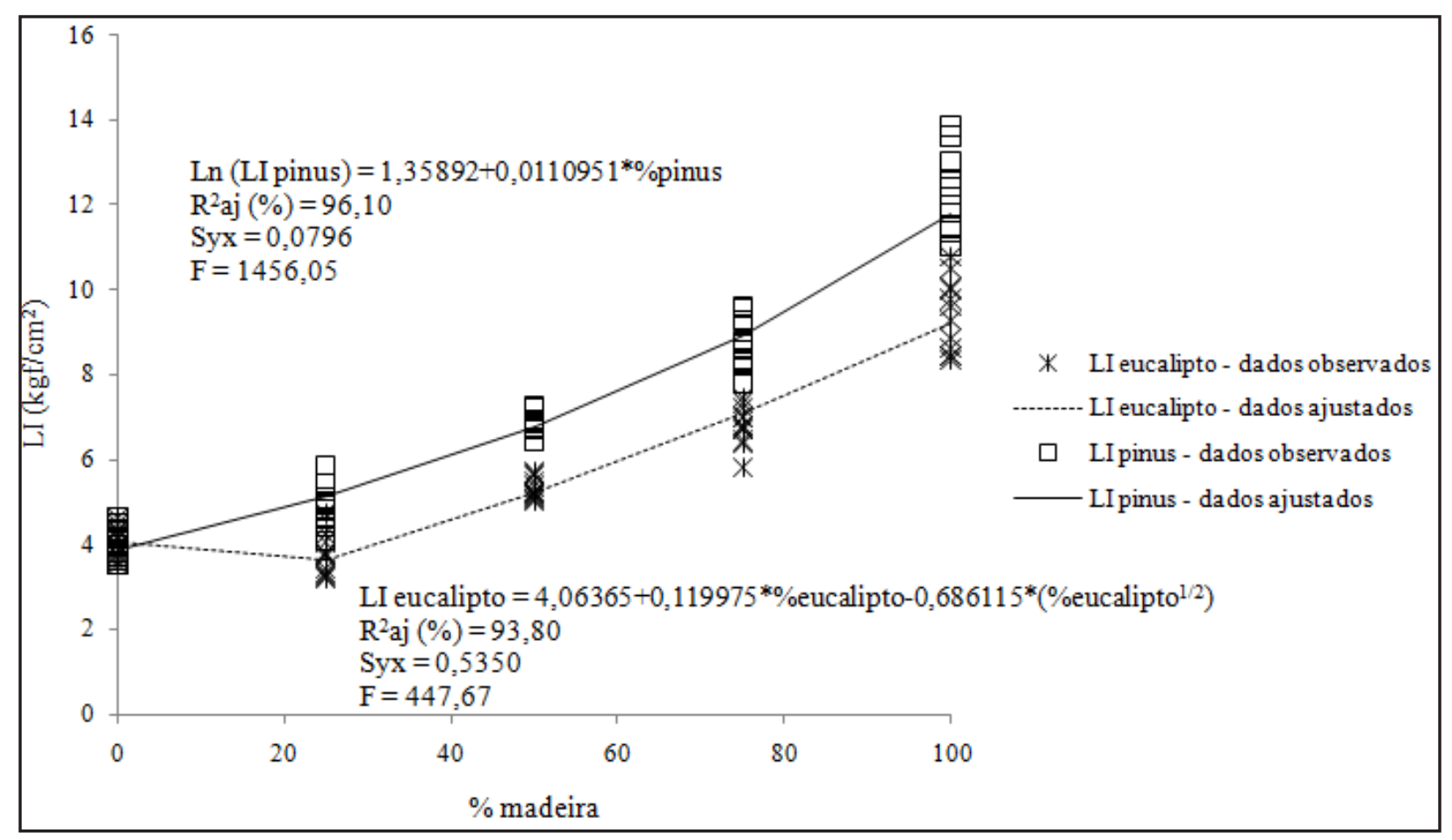

Fonte: Autores (2013)

Observa-se aqui um comportamento particular dos painéis com partículas de eucalipto combinados com cascas de arroz. O nível de $25 \%$ de partículas de eucalipto reproduz valores de LI inferiores ao nível de $0 \%$ dessas partículas. Como 
anteriormente discutido, esse fato pode ser atribuído a uma maior incompatibilidade das cascas de arroz com o cimento, sobretudo quando há presença de partículas de madeira na composição. O fato desses dois tipos de biomassa vegetal apresentarem incompatibilidade com o cimento já é muito discutido na literatura. Contudo, a combinação de cascas de arroz com partículas de madeira parece ampliar a conhecida incompatibilidade do cimento com esses materiais, gerando os resultados obtidos.

\section{CONCLUSÕES}

Com base nos resultados obtidos neste estudo, as seguintes conclusões são apresentadas:

Os painéis produzidos com partículas de pinus apresentaram piores características físicas, de forma que seu desempenho nos testes de absorção e inchamento em espessura para imersão de 24 horas foi inferior se comparado aos painéis fabricados à base de partículas de eucalipto.

A adição de cascas de arroz, porém, melhorou as propriedades físicas dos painéis fabricados tanto com partículas de pinus quanto com partículas de eucalipto. Quanto maior a quantidade de cascas de arroz adicionada à chapa, menores foram as taxas de absorção de água e inchamento em espessura.

As propriedades mecânicas dos painéis foram afetadas positivamente com o acréscimo de maiores quantidades de partículas madeireiras, tendo sido o pinus o material que apresentou melhores resultados para módulo de elasticidade e ligação interna. O eucalipto apresentou maiores valores de módulo de ruptura.

A adição de cascas de arroz representou perda de resistência mecânica para todos os tratamentos em todas as propriedades avaliadas.

Estudos mais aprofundados no nível inicial de interação entre partículas de eucalipto e casca de arroz poderão esclarecer o comportamento de queda de desempenho apresentado no teste de ligação interna.

Novas pesquisas que identifiquem as propriedades de painéis cimento-madeira 
obtidos com a mistura das duas espécies aqui estudadas e com a adição de cascas de arroz poderiam agregar conhecimento acerca do comportamento e da viabilidade de compósitos produzidos a partir desses três tipos de biomassa vegetal em conjunto.

\section{AGRADECIMENTOS}

Ao CNPQ pelo concedimento da bolsa de mestrado e produtividade em pesquisa.

\section{REFERÊNCIAS}

AMERICAN SOCIETY FOR TESTING AND MATERIALS. D 1037: Standard test methods for evaluating properties of wood-base fiber and particle panel materials. Philadelphia, 1999.

BERALDO, A. L. Compósitos Biomassa Vegetal-Cimento. In.: CONGRESSO BRASILEIRO DE ENGENHARIA AGRÍCOLA, 23., 1994, Campinas. Anais [...]. Campinas: SBEA, 1994. v. 1. p. 23.

BERALDO, A. L.; ZUCCO, L. L. Compósitos à base de cimento Portland: estudos efetuados para viabilizar o uso da casca de arroz. In: BALBUENA, R. H.; BENEZ, S. H.; JORAJURIA, D. Ingenieria rural y mecanización agraria em el ámbito latino americano.1. ed. La Plata: UNLP, 1998. p. 479-488.

BISON. Wood-cement board. Berlin: [s. n.], 1978. 10 p. (Bison-Reports, n. 8).

CARVALHO, J. V. Aproveitamento de resíduos particulados da madeira de Eucalyptus grandis na fabricação de compósitos à base de cimento Portland. 2000. Dissertação (Mestrado em Engenharia Agrícola) - Universidade Estadual de Campinas, Campinas, 2000.

DACOSTA, L. P. E. Utilização de resíduos do processamento mecânico da madeira para fabricação de chapas aglomeradas. 2004. Dissertação (Mestrado em Engenharia Florestal) Universidade Federal de Santa Maria, Santa Maria, 2004.

HILLIG, E. Qualidade de chapas aglomeradas estruturais, fabricadas com madeiras de Pinus, Eucalipto e Acácia-negra, puras ou misturadas, coladas com tanino-formaldeído. 2000. Dissertação (Mestrado em Engenharia Florestal) - Universidade Federal de Santa Maria, Santa Maria, 2000.

IWAKIRI, S. et al. Avaliação do potencial de utilização da madeira de Schizolobium amazonicum "Paricá" e Cecropia hololeuca "Embaúba" para a produção de painéis cimento-madeira. Cerne, Lavras, v. 18, n. 2, p. 303-308, 2012.

IWAKIRI, S. et al. Propriedades tecnológicas de painéis cimento-madeira produzidos com partículas de eucalipto. Ciências Agroveterinárias, Lages, v. 14, n. 3, p. 217-223, 2015.

LATORRACA, J. V. F. Estudo da viabilidade do uso da espécie Eucalyptus dunnii (Maid) na manufatura de painéis de madeira-cimento. 1996. Dissertação (Mestrado em Ciências Florestais) - Universidade Federal do Paraná, Curitiba, 1996. 
LATORRACA, J. V. F. Eucalyptus spp. na produção de painéis de cimento-madeira. 2000. Tese (Doutorado em Ciências Florestais) - Universidade Federal do Paraná, Curitiba, 2000.

LIPINSKI, E. Potencial tecnologies for effectivily bonding wood with inorganic binders. In.: INTERNATIONAL INORGANIC-BONDED WOOD AND FIBER COMPOSITE MATERIALS CONFERENCE, 1994, Washington. Proceedings [...]. Washington: Spokane, 1994. p. 53-58.

MACÊDO, A. N.; SOUZA, A. A. C.; POMPEU NETO, B. B. Chapas de cimento-madeira com resíduos da indústria madeireira da Região Amazônica. Ambiente Construído, Porto Alegre, v. 12, n. 2, p. 131-150, 2012.

MATOSKI, A. Utilização de pó de Madeira com granulometria controlada na produção de painéis de cimento-madeira. 2005. Tese (Doutorado em Ciências Florestais) - Universidade Federal do Paraná, Curitiba, 2005.

PIMENTEL, L. L. Telhas onduladas à base de cimento Portland e resíduos de Pinus caribeae. 2000. Dissertação (Mestrado em Engenharia Agrícola) - Universidade Estadual de Campinas, Campinas, 2000.

POMARICO, F. A. Potencial de utilização da madeira de clones de eucalipto na produção de painéis cimento-madeira.2013. Dissertação (Mestrado em Engenharia Florestal) Universidade Federal de Lavras, Lavras, 2013.

SERRANO, J. S.; CASTRO, J. V. Materiales de construcción com propriedades aislantes a base de cascara de arroz. Informes de La Construcción, Madri, v. 37, n. 7, p. 53-64, 1985.

SOUZA, M. R. Durability of cement-bonded particleboard made conventionally and carbon dioxide injection.1994. Thesis (Doctor of Philosophy) - University of Idaho, Idaho, 1994.

ZUCCO, L. L. Estudo da viabilidade de fabricação de placas de compósitos à base de cimento e casca de arroz. 1999. Dissertação (Mestrado em Engenharia Agrícola)- Universidade Estadual de Campinas, Campinas, 1999.

\section{Contribuição de Autoria}

\section{1 - Daniela Silva Lilge}

Engenheira Florestal, Dra., Professora

https://orcid.org/0000-0002-1062-3506•danielalilge@unipampa.edu.br

Contribuição: Curadoria de dados, Análise Formal, Investigação, Administração do projeto, Metodologia, Escrita - primeira redação, Escrita - revisão e edição 


\section{2 - Clovis Roberto Haselein}

Engenheiro Florestal, Dr., Professor

https://orcid.org/0000-0002-7329-9846•clovis.haselein@ufsm.br

Contribuição: Obtenção de financiamento, Análise Formal, Supervisão

\section{3 - Elio José Santini}

Engenheiro Florestal, Dr., Professor

https://orcid.org/0000-0003-0133-4654•santini@ufsm.br

Contribuição: Supervisão

\section{Como citar este artigo}

Lilge, D.S.; Haselein, C. R.; Santini, E. J. Avaliação do desempenho de painéis cimento-madeira fabricados com duas espécies florestais em combinação com casca de arroz. Ciência Florestal, Santa Maria, v. 31, n. 1, p. 20-42, 2021. DOI 10.5902/1980509810859. Disponível em: https:// doi.org/10.5902/1980509810859. Acesso em: xx mês abreviado 202x. 